\title{
Digestive System Dysplasia
}

National Cancer Institute

\section{Source}

National Cancer Institute. Digestive System Dysplasia. NCI Thesaurus. Code C95331.

A finding indicating the presence of morphologic features of neoplasia in the epithelium of any part of the digestive system without evidence of invasion. These features include architectural and cytological epithelial alterations. 